\section{Microbiologic quality of an untreated water sample analyzed by a novel DNA chip for simultaneous detection of microorganisms}

\author{
Filipa F. Vale, ${ }^{1}$ Kathy D. Saraiva-Pava, ${ }^{1}$ \\ Magda S.C. Fontes, ${ }^{1}$ Helena Vieira, ${ }^{2,3}$ \\ ${ }^{1}$ Faculty of Engineering, Catholic \\ University of Portugal, Rio de Mouro; \\ ${ }^{2}$ Bioalvo S.A., Edificio ICAT, Campus da \\ FCUL, Lisbon; \\ ${ }^{3}$ Universidade de Lisboa, Faculdade de \\ Ciências, Centre for Biodiversity, \\ Functional and Integrative Genomics \\ (BioFIG), Campus da FCUL, Campo \\ Grande, Lisboa, Portugal
}

\begin{abstract}
Consumption of contaminated drinking water heavily contributes to the burden of gastrointestinal waterborne diseases. Conventional detection methodologies present several shortcomings, such as indirect measure of indicator species, low throughput and time consume. DNA chips have the potential to serve as surveillance systems for the simultaneous detection of pathogens overcoming these limitations. We have developed a DNA chip for simultaneous detection of multiple waterborne pathogens. Species specific DNA probes were implemented on a microarray, for microorganism detection. Present study reports the results of one untreated water sample analyzed by conventional methods and by the DNA chip. The results were concordant for the mandatory organisms (total coliforms, Escherichia coli, fecal enterococci) using both methods, reinforcing the utility and proof-ofconcept of the DNA chip. However, it is necessary a prior enrichment in a culture medium in order to obtain a positive signal using the DNA chip. The DNA chip may be a valuable distinctive tool for waterborne pathogens detection.
\end{abstract}

\section{Introduction}

The World Health Organization (WHO) states that almost one tenth of the global disease burden could be prevented by improving water supply, sanitation, and hygiene and water resources management. The same organization estimates that around 1.5 million deaths per year could be avoided if these measures were implemented. ${ }^{1}$ Water quality control is essential to assure the delivery of safe human consump- tion water. Conventional methods used to access microbiologic water quality rely on culture methods for detection of indicator bacteria. Culture methods have the advantage of being non expensive and are considered the reference methods. However, theses methods have several limitations, such as the time they consume, low throughput and limitations of representativity by indicator species.,3 DNA chips are promising tools for simultaneous detection of waterborne pathogens, overcoming culture methods limitations. ${ }^{4}$ DNA chips have the advantage of being high throughput (simply by increasing the number of testing probes in the chip), quick (do not depend on time consuming bacterial growth) and may detect stressed bacteria (that do not develop in conventional culture mediums, but still can infect the human host). Previously we have reported the design and construction of a DNA chip for simultaneous detections of microorganisms in water samples ${ }^{3,5}$ and its suitability in detecting genomic DNA isolated from a pure culture of Escherichia coli, one of the European Community mandatory indicator microorganism. ${ }^{5}$ The design and construction of the probes implemented on the chip are described in detail in Vale et al. (2009), ${ }^{3}$ and include probes for European Community mandatory and non mandatory microorganisms. The DNA chip also includes two control probes with randomly generated sequences. Probe spotting, covalent binding of probes to slides were done at Biocant (Portugal), after single-strand probe synthesis using 3' modified primers with a C6 spacer and pre-treatment of Codelink ${ }^{\circledR}$ slides (Surmodics, Eden Prairie, MN, USA). Each DNA chip consisted of four separate sub-arrays of probes. Probes were spotted on each array at three different concentrations (62.5 ng/ $/ \mathrm{L}, 125 \mathrm{ng} / \mathrm{\mu L}$, and $250 \mathrm{ng} / \mathrm{\mu L}$ ) and eight replicates of each probe were spotted and distributed semi-randomly in four grids for each concentration. Previously we have reported the suitability of the DNA chip for detecting genomic DNA of a pure culture of $E$. coli. ${ }^{5}$ In the present study we aim at comparing the performance of the DNA chip with a real water sample, collected from a captation point of a water treatment plant. The untreated water sample was analyzed by conventional culture methods and by the DNA Chip, in order to compare results on microbiological parameters.

\section{Materials and Methods}

\section{Water sampling}

One water sample was collected from a captation point of a water treatment plant. Two liters of the sample were used for culture method detection and one liter for DNA chip analysis. Sterilized $1 \mathrm{~L}$ flasks were used for
Correspondence: Filipa F. Vale, Faculty of Engineering, Catholic University of Portugal, Estrada Octavio Pato, 2635-631 Rio de Mouro, Portugal.

Tel. +351.214269 824 - Fax: +351.214269800 .

E-mail: filipavale@fe.lisboa.ucp.pt

Key words: DNA chip, simultaneous microorganism's detection, water quality, indicator bacteria, waterborne pathogen.

Acknowledgements: this work was supported by Calouste Gulbenkian Foundation, program environment and health 2005 .

Contributions: FFV, $\mathrm{VH}$, designed the experiment; FFV, KDSP, MSCF, performed experimental work; $\mathrm{FFV}$, wrote the paper.

Conflicts of interest: the authors declare no potential conflicts of interest.

Received for publication: 26 October 2011.

Revision received: 9 January 2012.

Accepted for publication: 8 February 2012.

This work is licensed under a Creative Commons Attribution NonCommercial 3.0 License (CC BYNC 3.0).

(C) Copyright FF. Vale et al., 2012

Licensee PAGEPress, Italy

Microbiology Research 2012; 3:e11

doi:10.4081/mr.2012.e11

water sampling. The water was transported at $4^{\circ} \mathrm{C}$ to the laboratory.

\section{Conventional culture methods}

Conventional culture methods were used to determine the microbiological quality of water. The membrane filtration method was used to filter $100 \mathrm{~mL}$ (or $1 \mathrm{~L}$ for Salmonella spp.) of water through a $0.45 \mu \mathrm{m}$ pore membrane and each membrane was incubated in an appropriate selective medium at proper temperature. Presumptive colonies were confirmed by additional use of selective media and biochemical or serological tests, according to the Portuguese regulation (Law number DL:236/ 1998) that transpose for national law the European Directives 75/440/CE (water quality of superficial water intended for human consumption) and 79/869/CE (analytical methods and sampling frequency of water intended for human consumption). Briefly, water samples were filtrated through sterile membranes of $0.45 \mu \mathrm{m}$ pore (Macherey-Nagel, Germany), using a vacuum pump (Vacuubrand, Germany). Membranes were incubated in a selective medium at an appropriate temperature: i) for detection of total coliform bacteria the membrane was incubated in m-lauryl sulfate agar (MLSA; Sigma-Aldricht, USA) medi- 
um at $36 \pm 2^{\circ} \mathrm{C}$ for 24 hours and the yellow colonies tested for absence of oxidase activity; ii) for detection of fecal coliform bacteria, the membrane was incubated in MLSA medium at $44 \pm 0.5^{\circ} \mathrm{C}$ for 24 hours and the yellow colonies tested for absence of oxidase activity; iii) for detection of $E$. coli an oxidase negative yellow colony, grown in MLSA medium, was transferred to Fluorocult medium (Merck, Germany) and tested for the presence of glucuronidase enzyme and for the production of indol from tryptophane after addition of Kovacs reagent (Merck, Germany); iv) for detection of fecal enterococci, the membrane was incubated in Slanetz and Bartley agar medium (Oxoid, Germany) at $36 \pm 2^{\circ} \mathrm{C}$ for 48 hours and the red colonies were transferred to the bile aesculin agar medium (Merck, Germany) and tested for the hydrolysis of aesculin (2); v) for detection of Pseudomonas spp. the membrane was incubated in Pseudomonas selective medium (Sanofi Diagnostics Pasteur, France) at $36 \pm 2^{\circ} \mathrm{C}$ for 48 hours and green presumptive colonies were tested for absence of oxidase activity, cultured in King A and King B media and incubated at $36 \pm 2^{\circ} \mathrm{C}$ for 1 to 4 days, King $\mathrm{A}$ and King positive results were confirmed as Pseudomonas aeruginosa and King A positive King B negative as Pseudomonas spp.; vi) and for detection of Salmonella spp. the membrane was enriched in buffered peptone water (Oxoid, Germany) at $36 \pm 2^{\circ} \mathrm{C}$ for 16 to 20 hours and then $0.1 \mathrm{~mL}$ of this culture was transferred into Rappaport-Vassiliadis medium (Oxoid, Germany) and incubated at $42 \pm 0.5^{\circ} \mathrm{C}$ for 18 to 24 hours, after incubation this culture was spread in brilliant green agar modified (BGA, Oxoid, Germany) and xylose-lysine-desoxycholate agar (XLD) and incubated at $36 \pm 2^{\circ} \mathrm{C}$, for $24 \pm 4$ h (Oxoid, Germany), and presumptive Salmonella spp. colonies found in BGA (red colonies surrounded by bright red medium) and XLD (red colonies with black centres) were confirmed using the culture media Kliger (lactose negative, glucose positive, gas positive, H2S positive), urea agar (negative reaction) and lysine descarboxilase broth (positive reaction).

\section{DNA extraction from water, label- ing and DNA chip hybridization}

After two filtrations of $100 \mathrm{~mL}$ each of the untreated water sample through sterile membranes of $0.45 \mu \mathrm{m}$ pore (Macherey-Nagel, Germany), using a vacuum pump (Vacuubrand, Germany), and the first membrane was incubated for 24 hours in Brain Heart Infusion medium and the second membrane directly used for DNA extraction. After culture, the biomass was recovered by centrifugation and the DNA extracted. In both cases the total genomic DNA was extracted using Wizard ${ }^{\circledR}$ Genomic DNA Purification Kit (Promega $^{\mathrm{TM}}$ Corp., USA) according to the manufacturer's protocol. The use of a previous step culture was made to test if the bacterial load in the water sample is sufficient to be detected by the DNA chip, or if its growth in an enrichment media is necessary in order to detect the microorganisms. Genomic DNA was resuspended in nuclease-free water and quantified using QUBIT $^{\circledR}$ (Invitrogen, UK). The DNAs were labeled with Cy3 dye using Nimblegen One-Color DNA labeling kit (Roche, Madison, USA), as previously described. ${ }^{5}$ Labeled total water genomic DNA obtained after culture was mixed with labeled positive control DNA (PCR amplified fragment of a plasmid with an insert DNA complementary to randomly generated sequence spotted at position C2). For labeling the manufacturer recommends the use of $1 \mu \mathrm{g}$ of total DNA, which is then amplified with random hexamers (Nimblegen One-Color DNA labelling kit, Roche, Madison, WI, USA). Labelled DNAs were hybridized in the chip at $55^{\circ} \mathrm{C}$, incubated overnight in a hybridization oven (Shel Lab, Cornelius, USA). After a series of washes in SSC, deionized water and isopropanol, the slides were dried with compressed N2. ${ }^{5}$ In the DNA chip the probes are spotted at three different dilutions (250, 125 and $62.5 \mathrm{ng} / \mathrm{\mu L})$. The high number of replicates of each probe (eight) and the semi-random distribution of the probes in each grid ${ }^{5}$ are used to control for the high variability inherent to the methodolo- gy, and to reduce hybridization artefacts, as suggested by others. ${ }^{6}$

Image acquisition and data analysis

Slides were scanned using the microarray scanner ScanArray Gx (Perkin Elmer, Waltham, MA, USA) and scanned images were analyzed using the ScanArray Express Software (version 4.0, Perkin Elmer) for spot identification and quantification of the fluorescent signal intensities. Spots with a median pixel intensity superior to 400 intensity units and with more than twice the mean local background were considered positive. Each probe was only considered positive if at least five out of the eight probe spots on the slide were positive. $^{5}$

\section{Results}

The untreated water analysis presented microbial contamination using either culture methods or DNA hybridization based methods (DNA chip). However, for the DNA chip the results were distinct for the direct extraction of DNA after filtration or the DNA extraction after prior enrichment step in a culture medium. Conventional culture methods of the untreated water sample produce the following results: $2282 \mathrm{cfu} / 100 \mathrm{~mL}$ of total coliforms, 282

Table1. Results obtained by the DNA chip and culture method for the untreated water sample.

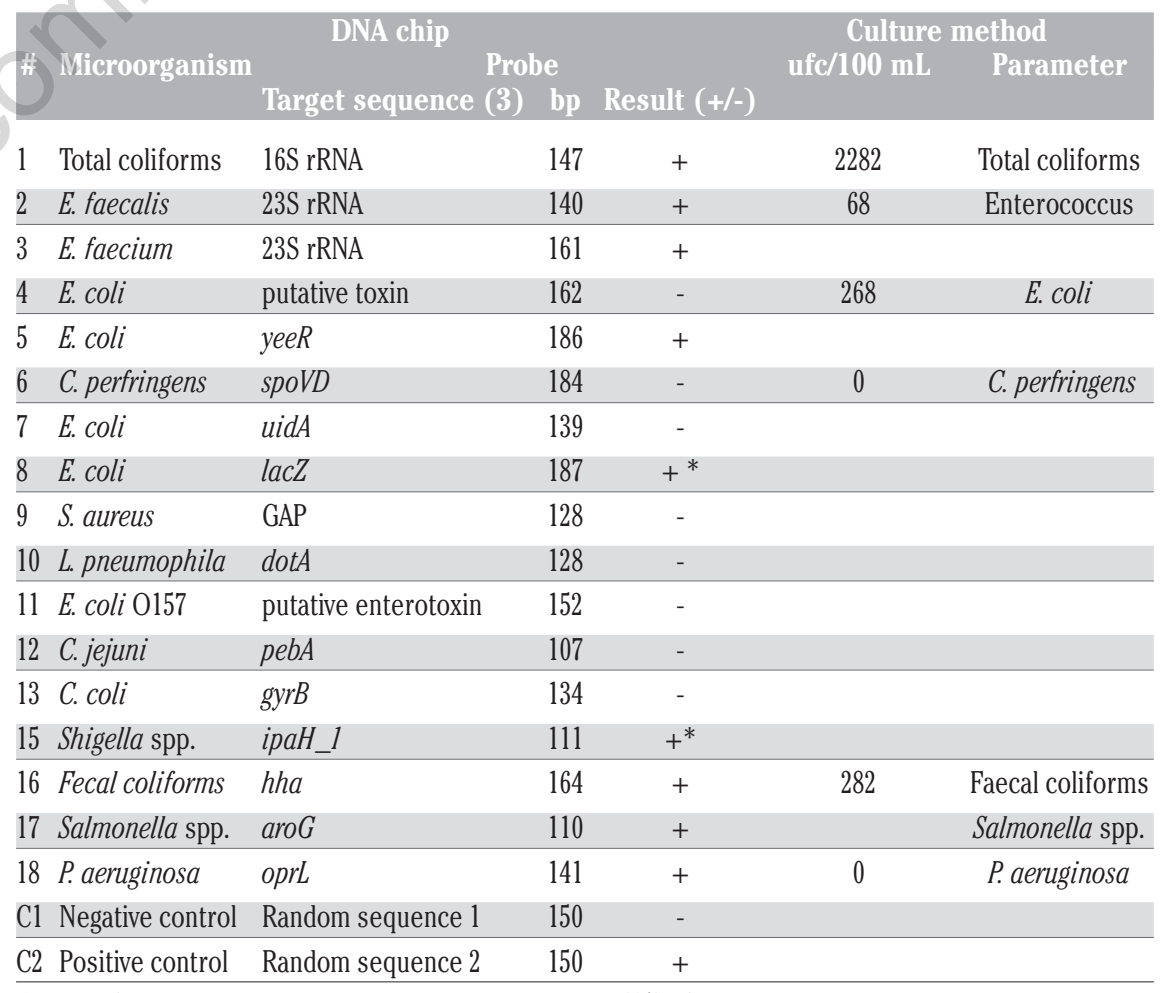

Absence in $1 \mathrm{~L}$. *Positive only in the sub-array with a probe concentration of $250 \mathrm{ng} / \mathrm{L}$. 
cfu/100 mL of fecal coliforms, $268 \mathrm{cfu} / 100 \mathrm{~mL}$ of $E$. coli, $68 \mathrm{cfu} / 100 \mathrm{~mL}$ of enterococcus, 0 $\mathrm{cfu} / 100 \mathrm{~mL}$ of Pseudomonas aeruginosa and absence of Salmonella spp. in 1 liter (Table 1). For DNA chip analysis it was necessary to extract total DNA directly after filtration or after an overnight culture in a rich medium (BHI). The concentration of the DNA was considerable different in each case, being 0.9 $\mu \mathrm{g} / \mathrm{mL}$ and $46.3 \mu \mathrm{g} / \mathrm{mL}$ for extraction after filtration of $100 \mathrm{~mL}$, and extraction after culture of $100 \mathrm{~mL}$ filtered water, respectively. After prior enrichment culture step, the concentration of the DNA increased about 50 times. The Nimblegen One-Colour DNA labelling kit (Roche, Madison, USA) recommends the use of $1 \mu \mathrm{g}$ of DNA for labeling, and the majority of the cases the extraction provided a smaller quantity of DNA. In these cases, all the amount of the DNA available was used for labeling. For DNA labeling it was used: the entire genomic DNA extracted $(0.008 \mu \mathrm{g})$ after filtration; $1 \mu \mathrm{g}$ of DNA extracted after culture; and $0.013 \mu \mathrm{g}$ of positive control DNA (all the amount of the PCR amplified fragment). After labeling the DNAs were resuspended in $100 \mu \mathrm{L}$ of hybridization solution and their concentration was: $0.4 \mu \mathrm{g} / \mathrm{mL}$ for positive control DNA, 57.2 $\mu \mathrm{g} / \mathrm{mL}$ for DNA extracted after filtration and $79.9 \mu \mathrm{g} / \mathrm{mL}$ for DNA extracted after culture. The hybridization of $2 \mu \mathrm{g}$ of labeled DNA extracted after filtration with the DNA chip did not give any positive spot (data not shown). The hybridization of $2 \mu \mathrm{g}$ of a mixture of positive control DNA and extracted DNA after culture produce positive results for total and fecal coliforms, E. coli, Enterococcus faecalis, $E$. faecium, Shigella spp, Salmonella spp. and Pseudomonas aeruginosa (Table 1 and Figure $1)$, for the sub-array with a probe concentration of $250 \mathrm{ng} / \mathrm{\mu L}$. Similar results were obtained with the sub-array with a probe of concentration $125 \mathrm{ng} / \mathrm{\mu L}$, except for the probes
8 and 15 (E. coli lacZ and Shigella spp.) that were negative at this probe concentration (Table 1). Probes spotted on the array at a concentration of $62.5 \mathrm{ng} / \mathrm{\mu L}$ only provide a positive result for positive control.

\section{Discussion}

We have presented previously reports with the first comparison of results of an untreated water sample analyzed by conventional culture methods and by the new DNA chip, in which the culture method is considering the reference method. The results from this study indicate that the DNA chip is equivalent to cultivation for delineating qualitatively positive/negative samples for the presence of waterborne bacteria, but only when a prior enrichment culture step is used. In fact, the hybridization of labeled DNA extracted after filtration without prior culture step did not provide any positive result. This has already been described by others, when performing a PCR for detection of Salmonella in water samples ${ }^{7}$ and when using an oligonucleotide-based microarray for the identification of Legionella spp. and other bacteria in water samples. ${ }^{8}$ The DNA chip did not detect any microorganism using the labeled DNA extracted directly after filtration (without pre-culture step); probably due to a concentration deficiency caused by the dilution of microorganisms in water, which provide small amounts of total genomic DNA. This indicates that DNA extraction after enrichment culture is more sensitive than direct DNA extraction for the detection of microorganisms in water. In fact, the dilution found in water samples makes difficult the detection of microorganism without a previous enrichment step. An alternative explanation is that there are inhibitors

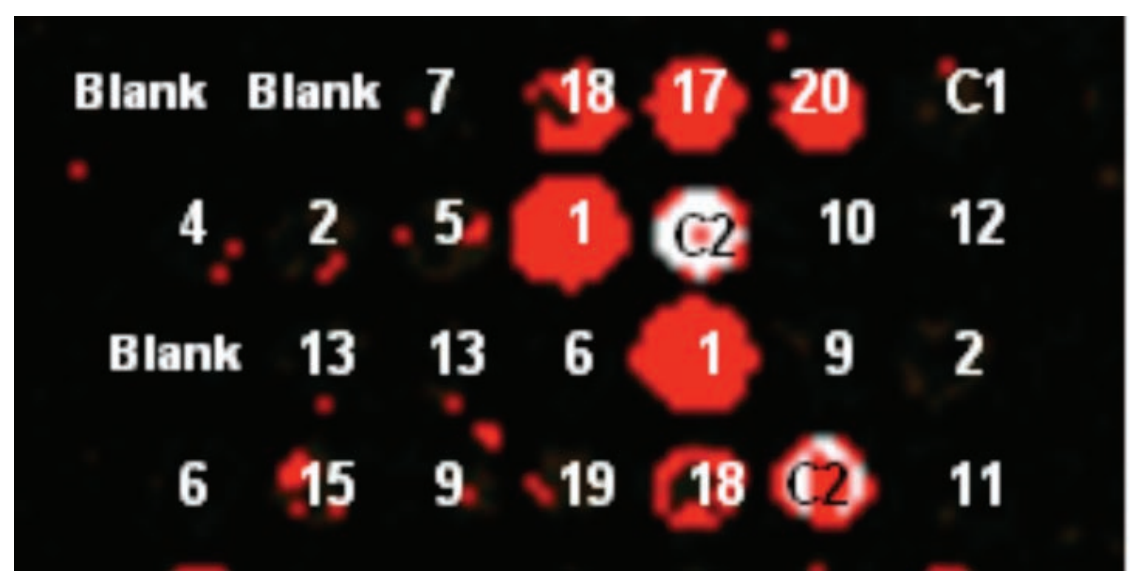

Figure 1. Partial fluorescent image of the DNA chip assay of the untreated water sample (probe concentration $250 \mathrm{ng} / \mu \mathrm{L}$ ). Consult Table 1 for probe number identification. of the hybridization, such as humic substances, matrices, and insoluble debris. ${ }^{7,9}$ This is clearly a limitation of molecular biology techniques for detection of waterborne pathogens. However, there are obvious advantages in hybridization techniques, such as simultaneous detection, rapidity and reduced time consumed, specificity and detection of stressed microorganisms.

Considering the low concentration of extracted DNA (without enrichment culture) it was not possible to label the recommended 1 $\mu \mathrm{g}$ of DNA. Increasing the filtrated volume, for instance for $1 \mathrm{~L}$ instead of $100 \mathrm{~mL}$ may help overcoming this limitation, but then the result provided for the chip would not respect the volume that should be analyzed according to the European Directives 75/440/CE and 79/869/CE. However, as these standards recommend the absence of contamination in drinking water, we consider that the increasing of the filtered volume would still permit obtaining important preliminary results. An alternative to diminish the time consumed in the DNA chip analysis would be the test of several hours of incubation and different enrichment media to select the most adequate one.

As expected only the sub-arrays presenting a higher probe concentration $(125 \mathrm{ng} / \mathrm{\mu L}$, and $250 \mathrm{ng} / \mathrm{\mu L}$ ), provide positive results. In fact, previously we have demonstrated that a higher probe concentration was more suitable for the analysis of a pure culture of E. coli. ${ }^{5}$ So, other DNA chips to be prepared should only contain these two probe concentrations $(125 \mathrm{ng} / \mathrm{\mu L}$, and $250 \mathrm{ng} / \mathrm{\mu L}$ ).

Using a pre-culture step there is a general agreement of results between our DNA chip and conventional methods. Discordant results were obtained for Pseudomonas spp. and Salmonella spp. (positive for the chip only) that may be explained by the already described existence of stressed bacteria unable to grow in selective media. ${ }^{10}$ Considering the positive result in the DNA chip for Salmonella probe the $95 \%$ homology to $E$. coli DNA, according to BLAST $^{11}$ (E-value 3E-28), may justify this signal. Discrepant results for Salmonella detection using culture methods and PCR has been described by others. ${ }^{7}$ In Hsu et al. study ${ }^{7}$ the use of Rappaport-Vassiliadis medium clearly diminishes the number of positive samples. In the present study the culture method for the detection of Salmonella also include a passage by Rappaport-Vassiliadis medium.

Results for positive control were as expected. The positive control is very useful for array alignment and identification of positive spots in samples of unknown composition. The DNA chip has several probes for $E$. coli, but probes 4 and 7 (Table 1) do not appear to be as suitable as the other ones (probes 5 and 8, Table 1).

Discrepancies between detection of microorganisms' nucleic acid sequences in 
water by the DNA chip and recovery of the bacterium on synthetic media have been noted in favor of the DNA chip, suggesting an increased sensibility of this method in comparison to culture methods.

In conclusion, the chip appears to be correctly identifying mandatory bacteria, but the probes for some of the non-mandatory microorganisms should be further evaluated. These results should be further confirmed increasing the number of analyzed water samples. Overall, the data gathered so far indicates that this type of approach might prove very suitable for immediate water analysis if an urgent response is required.

\section{References}

1. Prüss-Üstün A, Bos R, Gore F, Bartram J. Safer water, better health: costs, benefits and sustainability of interventions to protect and promote health. Geneva: World Health Organization; 2008. Available from: http://www.who.int/water_sanitation_heal th/publications/safer_water/en/
2. Silva AM, Vieira H, Martins N, et al. Viral and bacterial contamination in recreational waters: a case study in the Lisbon bay area. J Appl Microbiol 2010;108:1023-31.

3. Vale FF, Silva AM, Granja AT, et al. Simultaneous detection of micro-organisms in water samples for future chip applications: coliform bacteria, nonmandatory bacteria, hepatitis A virus and noroviruses. Phys Status Solidi C 2008;6:2184-9.

4. Lemarchand K, Masson L, Brousseau R. Molecular biology and DNA microarray technology for microbial quality monitoring of water. Crit Rev Microbiol 2004;30:145-72.

5. Martins N, Vale FF, Vieira H. Design and preliminary results of a DNA chip for the detection of microorganisms in water samples. Phys Status Solidi C 2010;7:27514.

6. Yauk CL, Williams A, Boucher S, et al. Novel design and controls for focused DNA microarrays: applications in quality assurance/control and normalization for the Health Canada ToxArray. BMC Genomics 2006;7:266.
7. Hsu BM, Huang KH, Huang SW, et al. Evaluation of different analysis and identification methods for Salmonella detection in surface drinking water sources. Sci Total Environ 2011;409:4435-41.

8. Zhou G, Wen S, Liu Y, et al. Development of a DNA microarray for detection and identification of Legionella pneumophila and ten other pathogens in drinking water. Int J Food Microbiol 2011;145:293-300.

9. Tebbe CC, Vahjen W. Interference of humic acids and DNA extracted directly from soil in detection and transformation of recombinant DNA from bacteria and a yeast. Appl Environ Microbiol 1993;59:2657-65.

10. Hussein HS, Bollinger LM. Influence of selective media on successful detection of Shiga toxin-producing Escherichia coli in food, fecal, and environmental samples. Foodborne Pathog Dis 2008;5:227-44.

11. Altschul SF, Madden TL, Schaffer AA, et al. Gapped BLAST and PSI-BLAST: a new generation of protein database search programs. Nucleic Acids Res 1997 1;25:3389402. 